\title{
Pathophysiological mechanism of long-term noninvasive ventilation in stable hypercapnic patients with COPD using functional respiratory imaging
}

\author{
This article was published in the following Dove Press journal: \\ International Journal of COPD \\ 28 July 2017 \\ Number of times this article has been viewed
}

\author{
Bita Hajian' \\ Jan De Backer ${ }^{2}$ \\ Claire Sneyers ${ }^{3}$ \\ Francisca Ferreira ${ }^{2}$ \\ Katherine C Barboza ${ }^{2}$ \\ Glenn Leemans' \\ Wim Vos ${ }^{2}$ \\ Wilfried De Backer' \\ 'Department of Respiratory Medicine, \\ University Hospital Antwerp, \\ ${ }^{2}$ FLUIDDA nv, ${ }^{3}$ Department of \\ Physical Medicine, Monica Hospital, \\ Antwerp, Belgium
}

\begin{abstract}
Introduction: Patients with severe COPD often develop chronic hypercapnic respiratory failure. Their prognosis worsens and they are more likely to develop exacerbations. This has major influence on the health-related quality of life. Currently, there is no information about the success of long-term noninvasive ventilation (NIV) among patients who receive NIV in acute settings. Also, little is known about the pathophysiological mechanism of NIV.

Methods: Ten Global Initiative for Obstructive Lung Disease stage III and IV COPD patients with respiratory failure who were hospitalized following acute exacerbation were treated with NIV using a Synchrony BiPAP device for 6 months. Arterial blood gases and lung function parameters were measured. Low-dose computed tomography of the thorax was performed and used for segmentation. Further analyses provided lobe volume, airway volume, and airway resistance, giving an overall functional description of the separate airways and lobes. Ventilation perfusion (VQ) was calculated. Patient-reported outcomes were evaluated.

Results: $\mathrm{PaCO}_{2}$ significantly improved from $50.03 \mathrm{mmHg}$ at baseline to $44.75 \mathrm{mmHg}$ after 1 month and $43.37 \mathrm{mmHg}$ after 6 months $(P=0.006)$. Subjects showed improvement in the 6-minute walk tests (6MWTs) by an average of $51 \mathrm{~m}$ (from $332 \mathrm{~m}$ at baseline to $359 \mathrm{~m}$ at 1 month and $383 \mathrm{~m}$ at 6 months). Patients demonstrated improvement in self-reported anxiety $(P=0.018)$. The improvement in image-based VQ was positively associated with the 6MWT and the anxiety domain of the Severe Respiratory Insufficiency Questionnaire.

Conclusion: Though previous studies of long-term NIV have shown conflicting results, this study demonstrates that patients can benefit from long-term NIV treatment, resulting in improved VQ, gas exchange, and exercise tolerance.
\end{abstract}

Keywords: noninvasive ventilation, COPD, functional respiratory imaging, ventilation perfusion, BiPAP, hypercapnia, exacerbations

\section{Introduction}

Chronic obstructive pulmonary disease (COPD) is a progressive disease that affects an increasing number of patients due to aging of the population. ${ }^{1}$ Some patients become especially handicapped with pronounced respiratory failure, sometimes with both severe hypoxia and hypercapnia. Pharmacological treatments in this population remain controversial. Systemic steroids have been shown to be beneficial by enhancing recovery during acute exacerbations and reducing hospital stays. ${ }^{2,3}$ They are, however, not suited for long-term treatment because of severe side effects. ${ }^{4}$ Inhaled steroids do not slow $\mathrm{FEV}_{1}$ decline but may prevent exacerbations in some patients, although the latter has
Correspondence: Bita Hajian University Hospital Antwerp, Wilrijkstraat 10, 2650 Edegem, Antwerp, Belgium Email bita.hajian@uza.be (c) (1) (5) 2017 Hajian et al. This work is published and licensed by Dove Medical Press Limited. The full terms of this license are available at https://www.dovepress.com/terms.php cc) and incorporate the Creative Commons Attribution - Non Commercial (unported, v3.0) License (http://creativecommons.org/licenses/by-nc/3.0/). By accessing the work you hereby accept the Terms. Non-commercial uses of the work are permitted without any further permission from Dove Medical Press Limited, provided the work is properly attributed. For permission for commercial use of this work, please see paragraphs 4.2 and 5 of our Terms (https://www.dovepress.com/terms.php). 
recently been questioned again. ${ }^{5}$ For these reasons, clinicians often have to rely on non-pharmacological treatments. ${ }^{6}$

Among these treatments, noninvasive ventilation (NIV) stands out as a possible effective therapy. Convincing evidence has been provided over the years for its use during acute exacerbations. ${ }^{7}$ Prediction factors, like the severity of hypercapnia and acidosis, have been defined. ${ }^{8}$ Chronic use NIV in stable hypercapnic COPD patients, however, remains very controversial. Initial studies and reviews have shown overall negative results, likely due to a lack of standardization of patients, different ventilator settings, and not well-standardized concomitant treatments..$^{9-11}$ However, with increasing experience and technological advances, it has become clear that some patients may benefit from this treatment. Moreover, NIV seems to be widely used even without clear evidence for its effectiveness. ${ }^{12,13}$ During the last decade, some groups have indicated that the lack of response may be due to the use of low inspiratory positive airway pressure (IPAP). Higher pressures are shown to be more effective but limit the use because of intolerance. ${ }^{14,15}$ Given the high unmet need in severe COPD patients and the clear indication that patients can benefit, we are urged to make significant progress in this field. A different approach to solve the outstanding question of defining responders is needed. For this, a better understanding of the pathophysiological effects induced by NIV, and its influence on patient-reported outcomes (PROs), is necessary. Among the relevant pathophysiological parameters are regional changes in airway caliber, perfusion, and ventilation perfusion ratio. The latter determines gas exchange, mainly hypoxemia, and has the potential to correlate with clinical markers such as exercise tolerance and quality of life. In a previous study, we showed that NIV can significantly redirect internal airflow presumably by opening partially or completely occluded airways, especially distal airways. ${ }^{16}$ When airflow is redirected toward well-perfused areas, the ventilation perfusion ratio may improve. In this study, arterial $\mathrm{PO}_{2}$ improved in some patients but regional changes in ventilation perfusion (VQ) were not measured directly.

The aim of the present study is to measure the ventilation and perfusion at the lobar level directly using functional respiratory imaging (FRI). ${ }^{17}$ The latter method directly measures airway caliber, airway resistance, regional flow, regional perfusion, and regional VQ. This study examined the most advanced FRI parameters to see whether these parameters changed during NIV and, more importantly, whether they correlated with PROs and exercise tolerance. This information sets the stage for algorithms that predict changes in these physiological parameters and can help identify responsive patients.

\section{Patients and methods}

Ten patients with Global Initiative for Obstructive Lung Disease (GOLD) stages III and IV COPD $\left(\mathrm{FEV}_{1}<50 \%\right.$, Tiffeneau $<70 \%$ ) participated in this study. Patients were included if they were 18-80 years of age, had a diagnosis of COPD GOLD III or IV $\left(\mathrm{FEV}_{1}<50 \%\right.$, Tiffeneau $<70 \%$ ), were hospitalized due to an exacerbation, and had developed persistent hypercapnia $\left(\mathrm{PaCO}_{2}>45 \mathrm{mmHg}\right)$ on day 5-12 under maximal pharmacological treatment. They must have stopped smoking and must not have had any treatment with home NIV before admission. Patients who were invasively ventilated and/or had been diagnosed with asthma, restrictive lung diseases, malignancy, heart failure, or obstructive sleep apnea syndrome were excluded. The approval of the local ethical committee was obtained.

Primary outcome variables were arterial blood gas values and functional imaging of the lungs. Secondary outcome variables were lung function tests (static and dynamic lung volumes, diffusion) and exercise tolerance.

NIV was provided with a Synchrony BiPAP device (Respironics, Inc, Murrysville, PA, USA), for $>5$ hours a day, with full face mask, starting 5-12 days after admission. Modes were adapted until $\mathrm{O}_{2}$ saturation was $>90 \%$ during $90 \%$ of the time and $\mathrm{PaCO}_{2}$ was decreased $5 \%$ in 1 hour. Patients were ventilated for at least 6 months and were followed up for 12 months.

Arterial blood gases were observed before starting NIV and again after 1 and 6 months. Between day 5 and 12, lung function tests and 6-minute walk tests (6MWTs) were performed and then repeated after 1 and 6 months. The following questionnaires were completed: the Saint George's Respiratory Questionnaire, Severe Respiratory Insufficiency (SRI) Questionnaire, visual analog scale Measure of Clinical Dyspnea, and UZA BiPAP. ${ }^{16-18}$

Low-dose high-resolution computed tomography (HRCT) scans were performed at baseline and after 1 and 6 months. One scan was taken at total lung capacity (TLC), the lung level attained after deep inspiration, and another was taken at functional residual capacity (FRC), the lung volume attained after a normal expiration. A handheld pneumotach was used for volume gating purposes to ensure scans were taken at the correct lung level.

The HRCT scans were then processed using the FRI approach which quantifies lobar volumes (iVlobes), airway volumes (iVaw), airway resistance (iRaw), and blood 
vessel volumes (iVbv). FRI provides more information on regional lung function characteristics (FLUIDDA, Kontich, Belgium).${ }^{14-16}$ HRCT images were imported into Mimics, a commercial, United States Food and Drug Administration (FDA)-approved, medical image processing software package (Materialise, Leuven, Belgium, FDA, K073468; CE certificate, BE 05/1191 CE01). This software package converts the HRCT images into patient-specific, three-dimensional (3D) computer models of the lung lobes and the airway tree, which can be segmented down to the bronchi with a diameter of $\sim 1-2 \mathrm{~mm}$. The 3D models were converted in a computational grid using a commercial software package (Mimics 15.0; Materialise NV, Leuven, Belgium; Food and Drug Administration, K073468; Conformité Européenne certificate, BE 05/1191.CE.01). Perfusion and ventilation were calculated separately for each lobe. Blood vessel density can be considered a surrogate for perfusion. Image-based perfusion (iQ) was calculated by blood vessel density at TLC multiplied by image volume at TLC. Image-based ventilation (iV) was calculated by the imaged volume at TLC subtracted from the image-based volume at FRC. This was calculated for the five lobes separately. The mean value of image-based ventilation perfusion match (iVQ) for each individual patient was calculated.

The study protocol was approved by the local ethics committee (Antwerp University Hospital) and written informed consent was obtained from each patient at the time of entry to the study. The study registration number is NCT01592656.

\section{Statistical analysis}

All statistical analyses were performed in $\mathrm{R}$ version 3.0.2 (R Foundation for Statistical Computing, Vienna, Austria). The statistical significance threshold was set to $P<0.05$ for all analyses.

Differences between the baseline, 1 month, and 6 month visits were assessed using linear mixed models, setting the visit as the fixed effect and the patient as the random effect. A posteriori $t$-test was performed to obtain the $P$-values between each of the two visits separately. These results are visualized by means of boxplots. In these figures, the extremes of the box represent the quartiles and the black line gives the median. The whiskers extend to the most extreme data point which is no more than 1.5 times the interquartile range from the box. All data points outside this range (outliers) are visualized as individual points. Asterisks indicate significant changes from baseline.

Correlations between clinical and FRI parameters were also assessed by linear mixed models. These results are visualized by standard $\mathrm{x}-\mathrm{y}$ plots where each dot represents a single measurement. The fitted line represents the fixed effect of the linear mixed model.

\section{Results}

Patients were treated with NIV using a maximal inspiratory pressure (IPAP) of $16.3 \pm 2.4 \mathrm{~cm} \mathrm{H}_{2} \mathrm{O}$, a minimal inspiratory pressure of $12.0 \pm 2.4 \mathrm{~cm} \mathrm{H}_{2} \mathrm{O}$ (average volume assured pressure support system used), and a mean expiratory

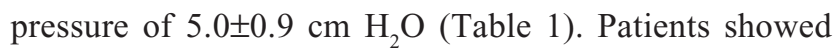
significant improvement in hypercapnia, with $\mathrm{PaCO}_{2}$ ranging from a mean of $50.03 \mathrm{mmHg}$ at baseline to $44.75 \mathrm{mmHg}$ after 1 month and $43.37 \mathrm{mmHg}$ after 6 months (Figure 1; $P=0.006$ ). Most patients who improved after 1 month also showed improvement after 6 months. Changes in $\mathrm{PaCO}_{2}$ were not accompanied by significant changes in lung volumes. Both FVC and TLC remained almost unchanged (Figure 2; $P=0.108$ ). Although improvement in the 6MWT was not statistically significant, the mean increase of $50 \mathrm{~m}$ (from $332 \mathrm{~m}$ at baseline to $359 \mathrm{~m}$ at 1 month and $383 \mathrm{~m}$ at 6 months) is clinically meaningful (Figure 3). Statistically significant changes were also found in the anxiety domain of the SRI questionnaire (Figure 4; $P=0.018$ ).

While the changes in airway resistance and airway volume were not statistically significant, results demonstrate a trend toward an increase in airway volume and decrease in airway resistance at 6 months (Figure 5). There was a significant negative correlation between the drop in $\mathrm{PaCO}_{2}$ and inspiratory capacity (Figure $6 ; P=0.01$ ). A similar correlation was seen between oxygen saturation at the end of the 6MWT and inspiratory capacity, indicating that hyperinflation goes along with more desaturation during exercise (Figure $7 ; P=0.03$ ). The SRI anxiety domain score was

Table I IPAP and EPAP pressures used during the study

\begin{tabular}{|c|c|c|c|c|c|}
\hline Patient ID & $\begin{array}{l}\text { Vt } \\
(\mathrm{mL})\end{array}$ & $\begin{array}{l}\text { bf } \\
\text { (BPM) }\end{array}$ & 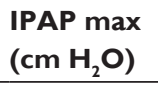 & $\begin{array}{l}\text { IPAP min } \\
\left(\mathrm{cm} \mathrm{H_{2 }} \mathrm{O}\right)\end{array}$ & $\begin{array}{l}\text { EPAP } \\
\left(\mathrm{cm} \mathrm{H} \mathrm{H}_{2} \mathrm{O}\right)\end{array}$ \\
\hline I & 350 & 12 & 16 & 12 & 4 \\
\hline 2 & 350 & 12 & 20 & 16 & 5 \\
\hline 3 & 400 & 12 & 17 & 13 & 6 \\
\hline 4 & 400 & 12 & 20 & 16 & 6 \\
\hline 5 & 400 & 10 & 14 & 10 & 4 \\
\hline 6 & 350 & 12 & 16 & 12 & 5 \\
\hline 7 & 350 & 12 & 16 & 12 & 6 \\
\hline 8 & 400 & 12 & 16 & 12 & 4 \\
\hline 9 & 300 & 12 & 12 & 8 & 4 \\
\hline 10 & 450 & 15 & 16 & 12 & 6 \\
\hline \multirow[t]{2}{*}{ Mean (SD) } & 375 & 12.1 & 16.3 & 12.3 & 5 \\
\hline & $(42.5)$ & $(1.2)$ & (2.4) & (2.4) & $(0.9)$ \\
\hline
\end{tabular}

Abbreviations: IPAP, inspiratory positive airway pressure; EPAP, expiratory positive airway pressure; $\mathrm{Vt}$, tidal volume; bf, breathing frequency. 


\section{Changes in $\mathrm{PaCO}_{2}$ during NIV}

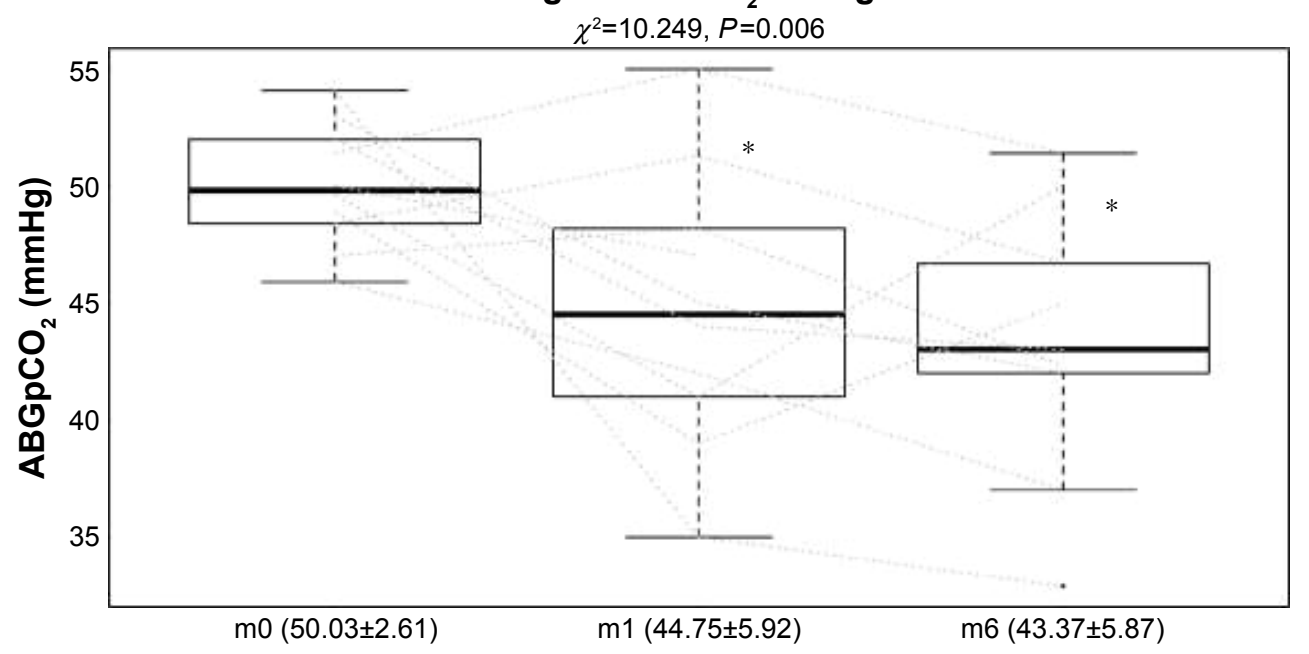

Figure I Patients treated with NIV saw significant improvements in $\mathrm{PaCO}_{2}$.

Notes: There is an important variability between the individual responses. The extremes of the box represent the quartiles and the black line gives the median. The whiskers extend to the most extreme data point which is no more than I.5 times the interquartile range from the box. All data points outside this range (outliers) are visualized as individual points. Asterisks indicate significant changes from baseline.

Abbreviations: NIV, noninvasive ventilation; ABG, arterial blood gas; m, month.

positively associated with an improvement in distal airway volume (Figure $8 ; P<0.001$ ). Improvement in VQ was also positively correlated with the 6MWT and the SRI anxiety domain score (Figure 9; $P<0.001 ; P=0.04$ ).

\section{Discussion}

In this study, we demonstrated that NIV provided to COPD patients following a hypercapnic exacerbation lowers their $\mathrm{PaCO}_{2}$ months later without requiring adjustments to pharmacological treatments. Exercise tolerance also appears to improve with NIV therapy, especially as associated with ventilation perfusion (VQ). A drop in hyperinflation is associated with improvement in blood gases. Therefore, improvement in VQ is probably due to increased ventilation.

It has been previously hypothesized that NIV can improve VQ relationships through recruitment of poorly ventilated lung units. ${ }^{18}$ However, this has not been confirmed in follow-up clinical studies with relevant intermediate outcome parameters. ${ }^{19} \mathrm{FRI}$ technology has made it possible to measure VQ at the lobar level in patients with hypercapnic COPD

\section{Lung volumes during NIV}

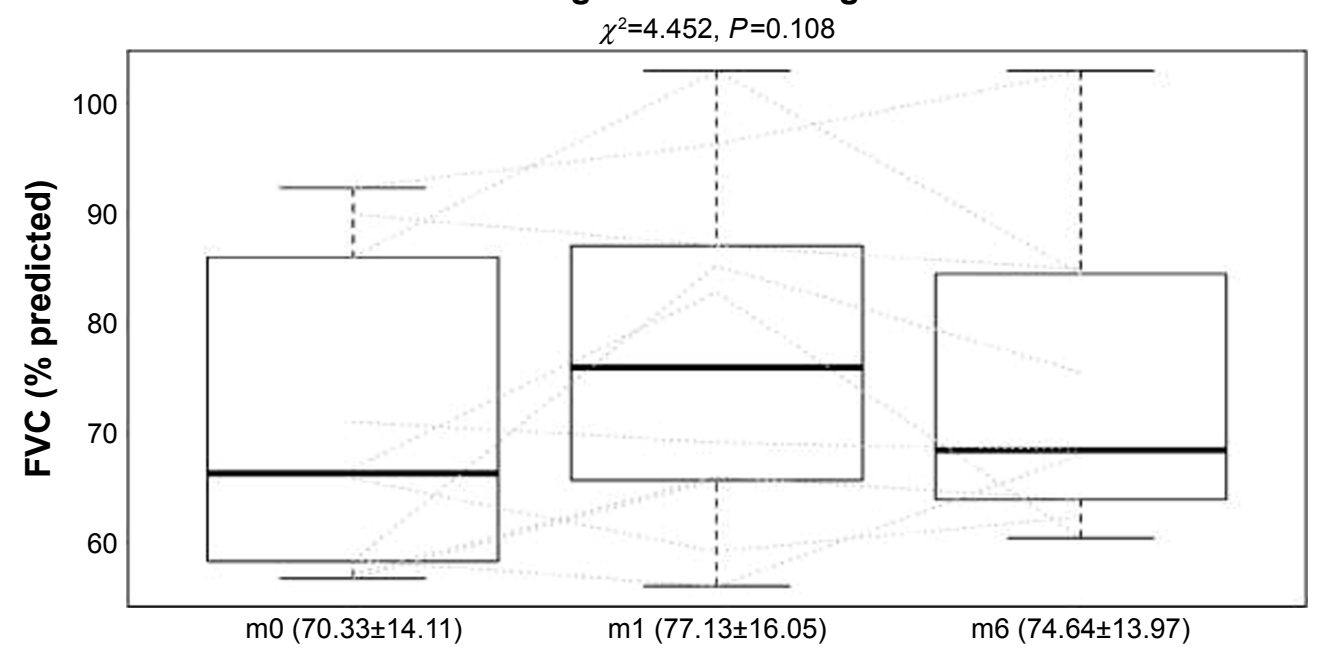

Figure 2 No significant changes in FVC were seen at I and 6 months of NIV treatment.

Notes: The extremes of the box represent the quartiles and the black line gives the median. The whiskers extend to the most extreme data point which is no more than 1.5 times the interquartile range from the box.All data points outside this range (outliers) are visualized as individual points. There was no significant change.

Abbreviations: NIV, noninvasive ventilation; FVC, forced vital capacity; m, month. 


\section{Exercise tolerance (6MWT) during NIV}

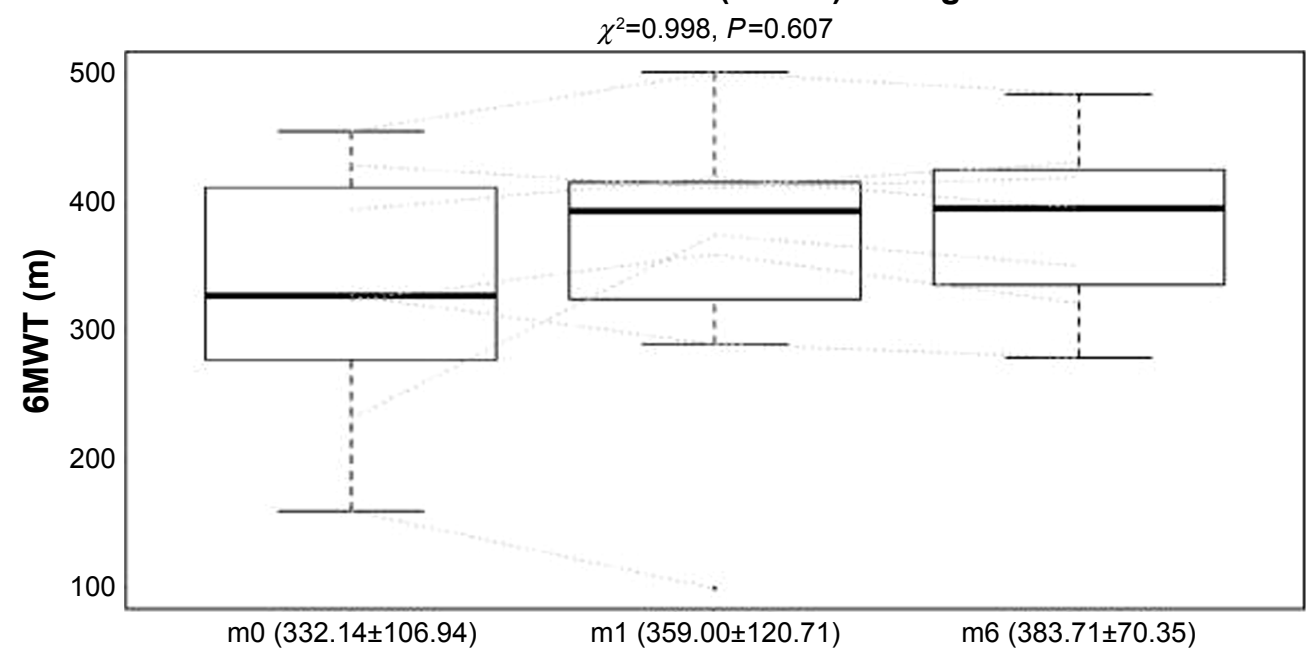

Figure 3 Improvements in the 6MWT were not statistically significant but a clinically meaningful mean increase of $51 \mathrm{~m}$ was found.

Notes: The extremes of the box represent the quartiles and the black line gives the median. The whiskers extend to the most extreme data point which is no more than I.5 times the interquartile range from the box. All data points outside this range (outliers) are visualized as individual points. There was no significant change.

Abbreviations: 6MWT, 6-minute walk test; NIV, noninvasive ventilation; m, month.

using long-term NIV, demonstrating tangible changes in VQ and its associated impact on relevant clinical outcomes like exercise tolerance and quality of life.

In an earlier controlled pilot study, we randomized 15 patients to a pharmacological treatment or to standard of care and NIV for 6 months. ${ }^{12}$ We assessed arterial blood gases and lung function parameters, and performed a lowdose computed tomography of the thorax with segmentation. Regional airway resistance and internal flow distribution were calculated using FRI. Blood gases, both hypoxia and hypercapnia, improved. There was a significant improvement in exercise tolerance as measured by the 6MWT. FRI showed remodeling after 6 months of treatment, with a redistribution of airflow toward well-perfused lobes in some patients, presumably due to the opening of partially or completely occluded airways, especially distally. ${ }^{16}$

It is hypothesized that the NIV ventilator settings may be important as higher inspiratory pressures will have more capacity to open up distal airways. Specifically, the mean inspiratory pressure and backup frequencies must be high

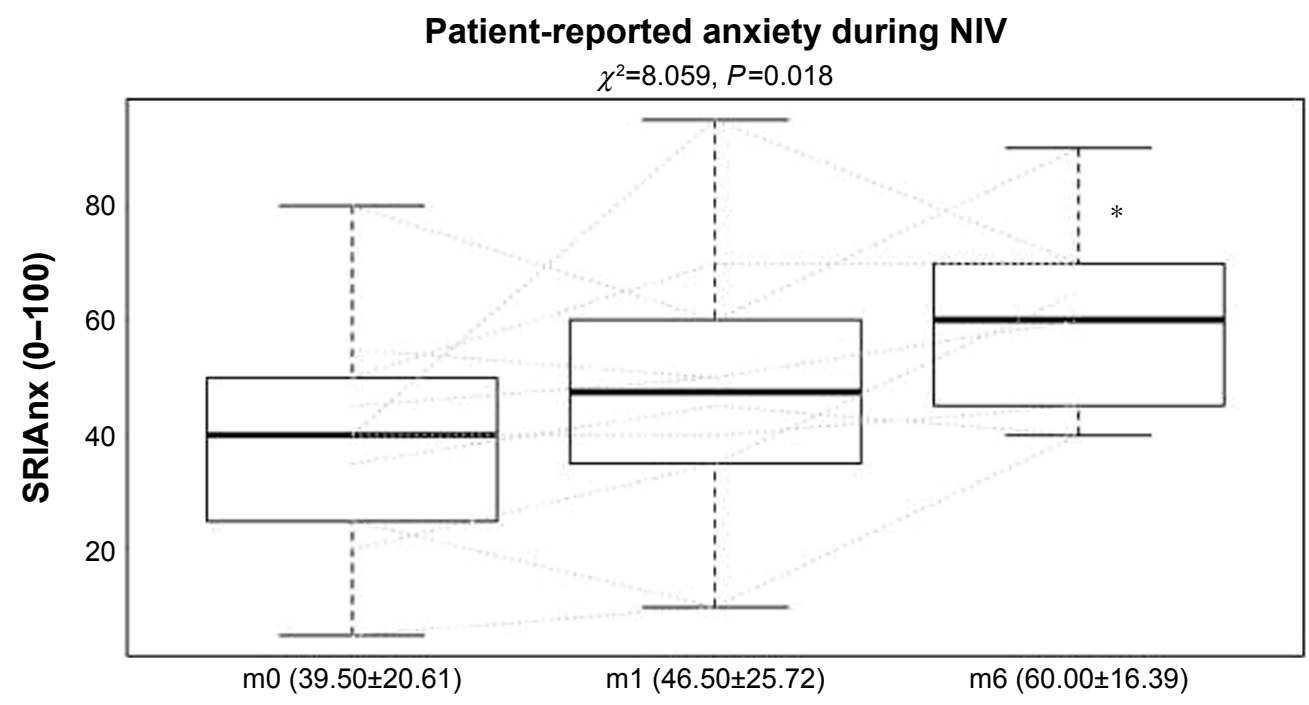

Figure 4 Patient-reported anxiety significantly improved after NIV treatment.

Notes: The extremes of the box represent the quartiles and the black line gives the median. The whiskers extend to the most extreme data point which is no more than I.5 times the interquartile range from the box. All data points outside this range (outliers) are visualized as individual points. Asterisk indicates significant changes from baseline. Abbreviations: NIV, noninvasive ventilation; SRIAnx, Severe Respiratory Insufficiency questionnaire anxiety domain score; m, month. 

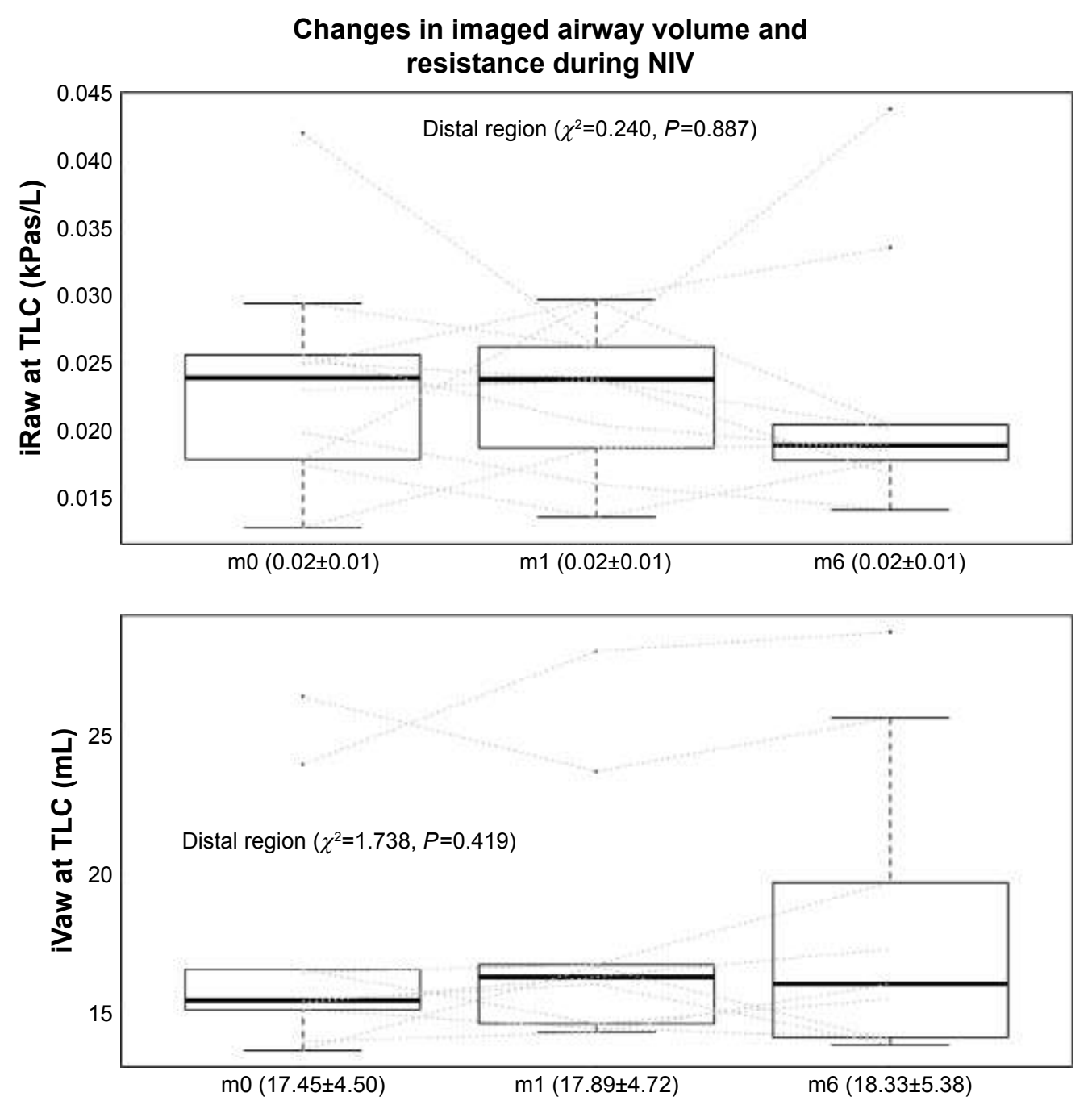

Figure $5 \mathrm{~A}$ trend toward an increase in iVaw and drop in iRaw was seen when measured at TLC.

Notes: The extremes of the box represent the quartiles and the black line gives the median. The whiskers extend to the most extreme data point which is no more than 1.5 times the interquartile range from the box. All data points outside this range (outliers) are visualized as individual points. There was no significant change.

Abbreviations: TLC, total lung capacity; NIV, noninvasive ventilation; iVaw, imaged airway volume; iRaw, imaged airway resistance; m, month.

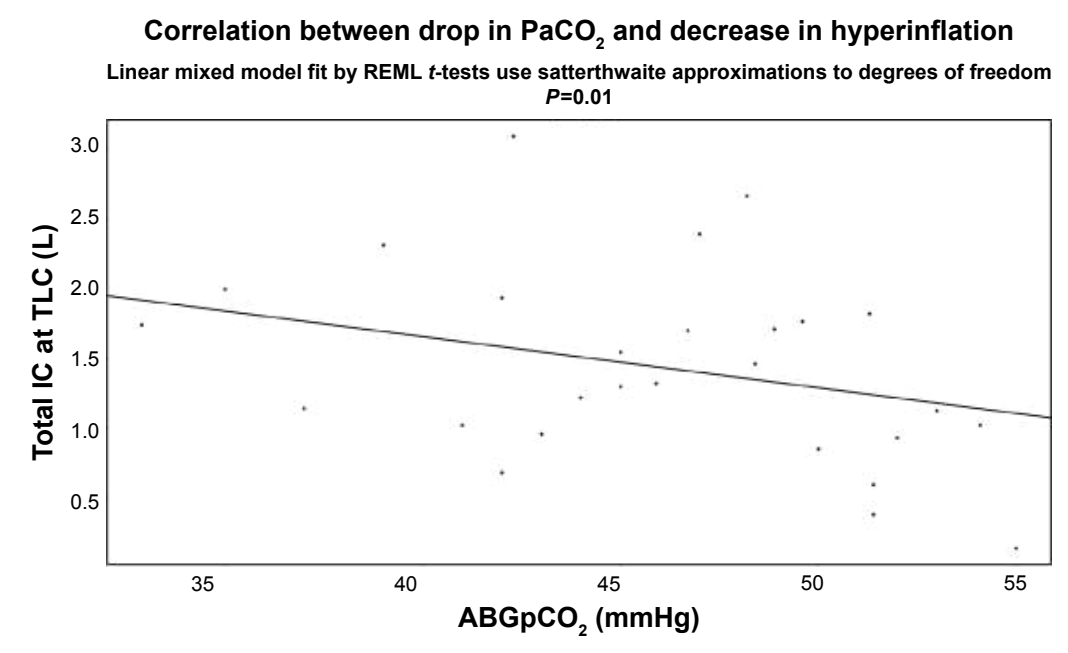

Figure 6 A significant correlation was found between a decrease in arterial $\mathrm{PCO}_{2}\left(\mathrm{ABGPCO}_{2}\right)$ and increase in IC.

Abbreviations: ABG, arterial blood gas; IC, inspiratory capacity; TLC, total lung capacity; REML, restricted maximum likelihood. 


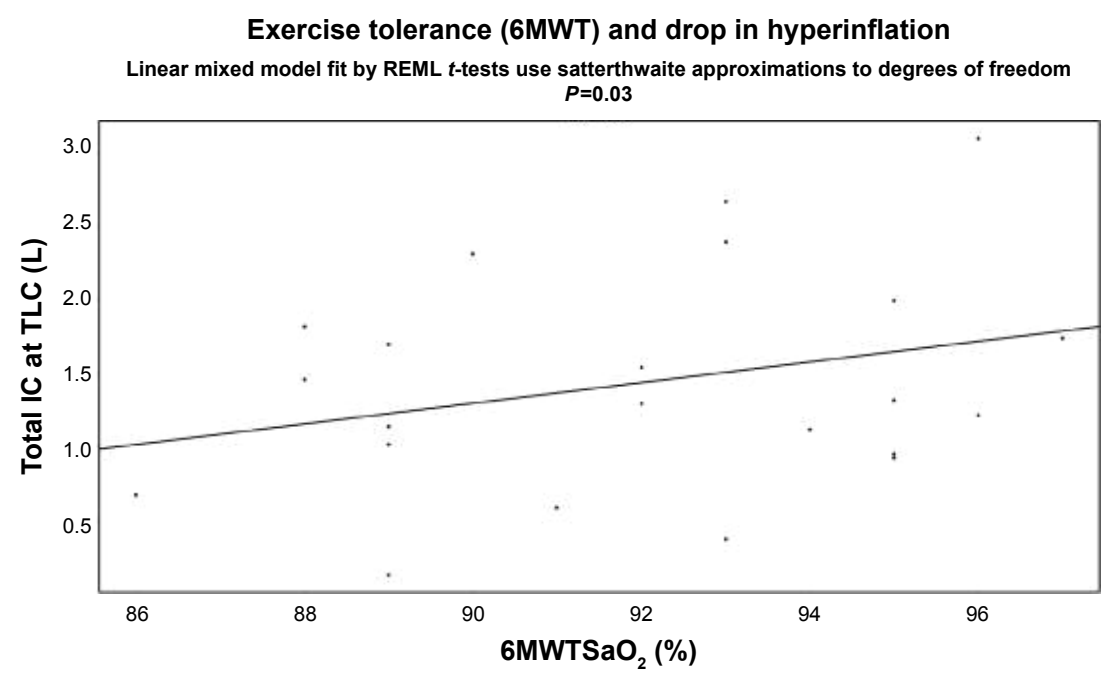

Figure $7 \mathrm{~A}$ significant correlation was found between an increase in oxygen saturation $\left(\mathrm{SaO}_{2}\right)$ during the 6MWT and IC.

Abbreviations: 6MWT, 6-minute walk test; IC, inspiratory capacity; TLC, total lung capacity; REML, restricted maximum likelihood.

enough to improve the alveolar ventilation and thereby reduce chronic hypercapnia. ${ }^{14,20}$ Köhnlein et al ${ }^{21}$ came to the same conclusion. They performed a large randomized controlled trial of 150 patients treated with NIV in an acute setting. They were randomized to usual standard of care or to continuing NIV for 1 year. They showed that, with effective ventilator strategies, it is possible to reduce hypercapnia significantly. This was associated with significant improvements in overall mortality ( $12 \%$ vs $33 \%$ for the controls), quality of life, and exercise capacity. In a recent study of 42 COPD patients with acute exacerbation, FRI technology demonstrated that an increase in distal airway resistance mainly led to hyperinflation and V/Q mismatch during the acute phase of an exacerbation. ${ }^{22}$ In the recovery phase, there was significant improvement in distal resistance and improvement in VQ.

Collectively, these studies suggest that exacerbation treatment should therefore be focused on improvement of distal airway resistance. By increasing the intraluminal airway pressure with NIV, distal airway resistance will reduce, providing a better VQ match, especially due to an increase in the ventilation related to a drop in distal airway resistance. Opening the distal airways with systemic therapy, ${ }^{23}$ inhaled therapy, and/or airway clearance techniques ${ }^{24-29}$ are adequate

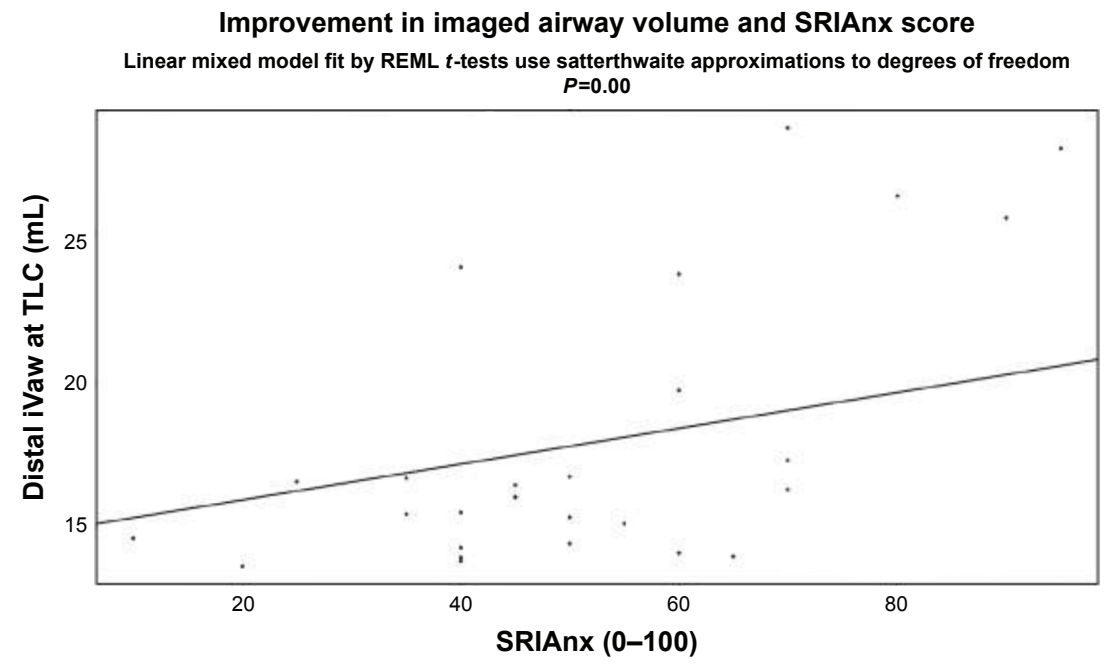

Figure 8 SRIAnx correlated with improvement in distal iVaw measured at TLC.

Abbreviations: SRIAnx, Severe Respiratory Insufficiency questionnaire anxiety domain score; TLC, total lung capacity; REML, restricted maximum likelihood; iVaw, imaged airway volume. 

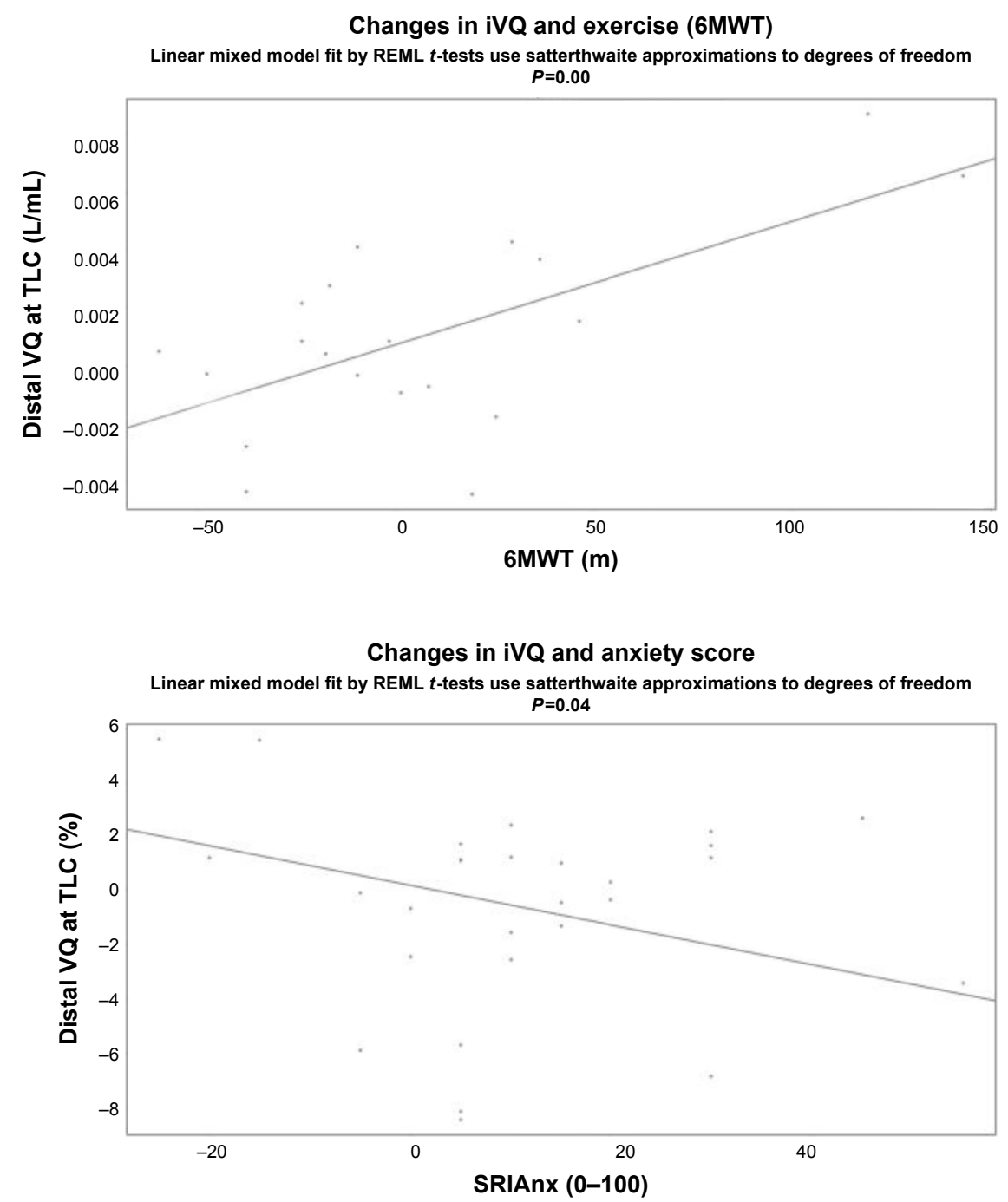

Figure 9 Improvement in iVQ correlated significantly with improvement in the 6MWT (upper panel) and SRIAnx (lower panel).

Abbreviations: SRIAnx, Severe Respiratory Insufficiency questionnaire anxiety domain score; TLC, total lung capacity; REML, restricted maximum likelihood; 6MWT, 6-minute walk test; VQ, ventilation perfusion; iVQ, imaged-based ventilation perfusion.

treatments for COPD exacerbation and persistent respiratory failure due to COPD.

Lastly, improvement in distal airway resistance can also lead to improved PROs and can therefore be considered as a useful surrogate clinical marker. In this study, patients improved their exercise capacity with an average increase of $51 \mathrm{~m}$ in the $6 \mathrm{MWT} .{ }^{30}$ Self-reported anxiety also improved over the course of treatment. These findings demonstrate that the observed changes in physiological parameters have a clinical meaning.

There has been a long debate about the usefulness of NIV in the chronic treatment of COPD. While some overviews argue against the chronic use of NIV in these patients, this study demonstrates that patients can benefit from treatment via improved VQ leading to improved gas exchange and thereby better exercise tolerance. However, not all patients respond to this treatment. Nevertheless, this is not a reason to withhold treatment from all patients, especially when we now are realizing that responders can have significant benefit.

FRI allows us to measure relevant surrogate physiological markers, like VQ, and correlate them with clinical outcomes. It offers the possibility of detecting responders in early phases of treatment and establishing stopping rules.

\section{Acknowledgment}

J Aerts, J Clukers, and V Verplancke also contributed to this research.

\section{Disclosure}

J De Backer, W Vos, F Ferreira, and KC Barboza are affiliated with Fluidda NV. The authors have no other relevant 
affiliations or financial involvement with any organization or entity with a financial conflict with the subject matter or materials discussed in the manuscript apart from those disclosed.

\section{References}

1. Ambrosino N, Simonds A. The clinical management in extremely severe COPD. Respir Med. 2007;101(8):1613-1624.

2. Walters JA, Tan DJ, White CJ, Wood-Baker R. Different durations of corticosteroid therapy for exacerbations of chronic obstructive pulmonary disease. Cochrane Database Syst Rev. 2014;12:CD006897.

3. Burgel PR. Toward personalized prescription of systemic steroids for patients hospitalized with COPD exacerbations. Chest. 2016; 150(2):268-269.

4. Garvey C. Recent updates in chronic obstructive pulmonary disease. Postgrad Med. 2016;128(2):231-238.

5. Calverley PM, Anderson JA, Celli B, et al. Salmeterol and fluticasone propionate and survival in chronic obstructive pulmonary disease. N Engl J Med. 2007;356(8):775-789.

6. Elliott MW. Non-invasive ventilation for acute respiratory disease. Br Med Bull. 2004;72:83-97.

7. Pisani I, Comellini V, Nava S. Noninvasive ventilation versus oxygen therapy for the treatment of acute respiratory failure. Expert Rev Respir Med. 2016;10(7):813-821.

8. Pastaka C, Kostikas K, Karetsi E, Tsolaki V, Antoniadou I, Gourgoulianis KI. Non-invasive ventilation in chronic hypercapnic COPD patients with exacerbation and a $\mathrm{pH}$ of 7.35 or higher. Eur $J$ Intern Med. 2007;18(7):524-530.

9. Wijkstra PJ, Lacasse Y, Guyatt GH, et al. A meta-analysis of nocturnal noninvasive positive pressure ventilation in patients with stable COPD Chest. 2003;124(1):337-343.

10. Struik FM, Lacasse Y, Goldstein RS, Kerstjens HA, Wijkstra PJ. Nocturnal noninvasive positive pressure ventilation in stable COPD: a systematic review and individual patient data meta-analysis. Respir Med. 2014;108(2):329-337.

11. Struik FM, Sprooten RT, Kerstjens HA, et al. Nocturnal non-invasive ventilation in COPD patients with prolonged hypercapnia after ventilatory support for acute respiratory failure: a randomised, controlled, parallel-group study. Thorax. 2014;69(9):826-834.

12. Roberts CM, Lopez-Campos JL, Pozo-Rodriguez F, Hartl S; European COPD Audit team. European hospital adherence to GOLD recommendations for chronic obstructive pulmonary disease (COPD) exacerbation admissions. Thorax. 2013;68(12):1169-1171.

13. Crimi $\mathrm{C}$, Noto A, Princi $\mathrm{P}$, et al. Domiciliary non-invasive ventilation in COPD: an international survey of indications and practices. COPD 2016;13(4):483-490.

14. Windisch W, Storre JH, Köhnlein T. Nocturnal non-invasive positive pressure ventilation for COPD. Expert Rev Respir Med. 2015;9(3): 295-308.

15. Köhnlein T, Windisch W, Kohler D, et al. Non-invasive positive pressure ventilation for the treatment of severe stable chronic obstructive pulmonary disease: a prospective, multicentre, randomised, controlled clinical trial. Lancet Respir Med. 2014;2(9):698-705.
16. Kinsella JP, Abman SH. Inhaled nitric oxide in the premature infant: animal models and clinical experience. Semin Perinatol. 1997;21(5): 418-425.

17. Hajian B, De Backer J, Vos W, Van Holsbeke C, Clukers J, De Backer W. Functional respiratory imaging (FRI) for optimizing therapy development and patient care. Expert Rev Respir Med. 2016;10(2):193-206.

18. Diaz O, Iglesia R, Ferrer M, et al. Effects of noninvasive ventilation on pulmonary gas exchange and hemodynamics during acute hypercapnic exacerbations of chronic obstructive pulmonary disease. Am J Respir Crit Care Med. 1997;156(6):1840-1845.

19. Struik FM, Lacasse Y, Goldstein R, Kerstjens HM, Wijkstra PJ. Nocturnal non-invasive positive pressure ventilation for stable chronic obstructive pulmonary disease. Cochrane Database Syst Rev. 2013; 6:CD002878.

20. Dreher M, Storre JH, Schmoor C, Windisch W. High-intensity versus low-intensity non-invasive ventilation in patients with stable hypercapnic COPD: a randomised crossover trial. Thorax. 2010;65(4):303-308.

21. Köhnlein T, Criee CP, Kohler D, Welte T, Laier-Groeneveld G. Multizentrische Studie: "Nicht-invasive Beatmung bei Patienten mit schwerer chronisch obstruktiver Bronchitis und Emphysem (COPD)" [Multicenter study on "non-invasive ventilation in patients with severe chronic obstructive pulmonary disease and emphysema (COPD)"] Pneumologie. 2004;58(8):566-569. German.

22. Hajian B, Vos W, Van Holsbeke C, et al. Changes in ventilationperfusion during and after COPD exacerbation: an assessment using functional respiratory imaging. COPD. In press 2017.

23. Vos W, Hajian B, De Backer J, et al. Functional respiratory imaging to assess the interaction between systemic roflumilast and inhaled ICS/LABA/LAMA. Int J Chron Obstruct Pulmon Dis. 2016;11: 263-271.

24. Hajian B, De Backer J, Vos W, Aerts J, Cluckers J, De Backer W. Efficacy of inhaled medications in asthma and COPD related to disease severity. Expert Opin Drug Deliv. 2016;13(12):1719-1727.

25. De Backer W, Vos W, Van Holsbeke C, et al. The effect of roflumilast in addition to LABA/LAMA/ICS treatment in COPD patients. Eur Respir J. 2014;44(2):527-529.

26. Burgel PR, Bourdin A, Chanez P, et al. Update on the roles of distal airways in COPD. Eur Respir Rev. 2011;20(119):7-22.

27. Burgel PR, de Blic J, Chanez P, et al. Update on the roles of distal airways in asthma. Eur Respir Rev. 2009;18(112):80-95.

28. Ides K, Vos W, De Backer L, et al. Acute effects of intrapulmonary percussive ventilation in COPD patients assessed by using conventional outcome parameters and a novel computational fluid dynamics technique. Int J Chron Obstruct Pulmon Dis. 2012;7:667-671.

29. Vissers D, Baeyens JP, Truijen S, Ides K, Vercruysse CC, Van Gaal L. The effect of whole body vibration short-term exercises on respiratory gas exchange in overweight and obese women. Phys Sportsmed. 2009;37(3):88-94.

30. Bohannon RW, Crouch R. Minimal clinically important difference for change in 6-minute walk test distance of adults with pathology: a systematic review. J Eval Clin Pract. 2017;23(2):377-381.
International Journal of COPD

\section{Publish your work in this journal}

The International Journal of COPD is an international, peer-reviewed journal of therapeutics and pharmacology focusing on concise rapid reporting of clinical studies and reviews in COPD. Special focus is given to the pathophysiological processes underlying the disease, intervention programs, patient focused education, and self management protocols.

\section{Dovepress}

This journal is indexed on PubMed Central, MedLine and CAS. The manuscript management system is completely online and includes a very quick and fair peer-review system, which is all easy to use. Visit http://www.dovepress.com/testimonials.php to read real quotes from published authors. 